\title{
Características da ingestão de forragem por cordeiras nos estádios fenológicos da pastagem de azevém
}

[Characteristics of forage intake of lambs at phenological stages of Italian ryegrass pasture]

\author{
D.G. Camargo ${ }^{1}$, M.G. Rocha ${ }^{2 *}$, J.H.S. Silva ${ }^{2}$, C.L. Glienke ${ }^{1}$, \\ A.C.C. Confortin ${ }^{1}$, J. M. Machado ${ }^{3}$ \\ ${ }^{1}$ Aluna de pós-graduação - Universidade Federal de Santa Maria - Santa Maria, RS \\ ${ }^{2}$ Universidade Federal de Santa Maria - Santa Maria, RS \\ ${ }^{3}$ Universidade Federal do Rio Grande do Sul - Porto Alegre, RS
}

\begin{abstract}
RESUMO
Foram estudadas as características do processo de ingestão de forragem por cordeiras em azevém (Lolium multiflorum Lam.) nos estádios fenológicos vegetativo, pré-florescimento e florescimento, por meio de testes de pastejo e da técnica da dupla pesagem. O delineamento experimental foi o inteiramente ao acaso, com três tratamentos e cinco repetições no estádio vegetativo e seis nos demais estádios. Os diferentes estádios fenológicos não influenciam a taxa de ingestão, a massa do bocado e a profundidade de bocado quando a oferta de forragem não é limitante ao consumo. O aumento na taxa de bocados é o mecanismo utilizado por cordeiras para manter a taxa de ingestão constante. Os modelos de regressão múltipla indicam que, dentre os atributos do pasto, sua altura é o de maior importância para determinar mudanças no comportamento ingestivo de cordeiras.
\end{abstract}

Palavras-chave: estrutura do pasto, Lolium multiflorum, massa do bocado, profundidade de bocado, taxa de ingestão

\begin{abstract}
Utilizing grazing tests and the double weighing technique, the characteristics of the forage intake process of lambs grazing Italian Ryegrass pasture at vegetative, pre-flowering and flowering phenological stages were studied. A completely randomized design with three treatments and five replicates in the vegetative stage and six replicates in the other phenological stages was used. The intake rate, bite mass and bite depth were not influenced by the phenological stages when the intake was not limited by the forage allowance. By increasing bite rate lambs maintained a constant rate of intake. The multiple regression models indicate that among the herbage attributes, the sward height is the most important to determine changes in the grazing behavior of lambs on Italian Ryegrass pasture.
\end{abstract}

Keywords: forage structure, Lolium multiflorum, bite mass, bite depth, intake rate

\section{INTRODUÇÃO}

As relações planta-animal em pastagem, com ênfase no processo de ingestão de forragem, vêm sendo estudadas desde a década de 60, tendo como referencial a pesquisa de Allden (1962). Os resultados desses estudos mostram que o desempenho animal depende diretamente da ingestão diária de matéria seca (MS) e que essa ingestão varia em função dos efeitos do processo de pastejo sobre a produção de forragem e a estrutura do dossel (Cosgrove, 1997). No Brasil, essa é uma linha de pesquisa ainda em expansão, e a literatura disponível apresenta resultados, em sua maioria, em espécies forrageiras tropicais (Palhano et al., 2007) que não estão entre as espécies de maior área de cultivo no estado do Rio Grande do Sul.

Recebido em 20 de julho de 2011

Aceito em 10 de janeiro de 2012

* Autor para correspondência (corresponding author)

E-mail:mgdarocha@gmail.com 
A ingestão diária de forragem foi considerada por Allden e Wittaker (1970) como o produto entre o tempo gasto pelo animal na atividade de pastejo e a taxa de ingestão de forragem durante o pastejo, que, por sua vez, é o produto do número de bocados por unidade de tempo (taxa de bocados) e da quantidade de forragem apreendida em cada bocado (massa do bocado). $\mathrm{O}$ consumo de forragem pelo animal em pastejo foi abordado em duas dimensões temporais, no longo prazo - ingestão diária de MS - e no curto prazo - taxa de ingestão de MS. A ingestão diária de MS seria dependente do tempo de pastejo e da digestão do alimento consumido (Laca e Demment, 1992), enquanto a taxa de ingestão estaria diretamente relacionada às características do pasto e à sua influência sobre a velocidade de manipulação e ingestão da forragem disponível (Gonçalves, 2007).

A estrutura do pasto é influenciada pelo manejo imposto, pelo estádio fenológico da planta e pela interação entre eles. A variação temporal na qualidade e na quantidade de forragem disponível é fisiológica, e, como consequência dessa variação, os herbívoros desenvolvem estratégias de pastejo, ao longo do ciclo do pasto, como um meio de compensar essas modificações. O conhecimento dessas estratégias pode ser uma importante ferramenta para estabelecer um manejo de pastagens que permita otimizar a utilização da forragem e conferir eficiência ao sistema.

Este trabalho foi realizado com o objetivo de estudar as características do processo de ingestão de forragem de cordeiras em azevém (Lolium multiflorum Lam.), partindo da hipótese de que os diferentes estádios fenológicos da planta influenciam as relações planta-animal no processo de captura do alimento por cordeiras em pastejo.

\section{MATERIAL E MÉTODOS}

O experimento foi desenvolvido no período de maio a novembro de 2007, no Rio Grande do Sul, cujas coordenadas são $29^{\circ} 43^{\prime} \mathrm{S}, 53^{\circ} 42^{\prime} \mathrm{O}$. A área experimental correspondeu a $1.200 \mathrm{~m}^{2}$, onde a pastagem foi estabelecida pelo sistema convencional, no dia $1^{\circ}$ de maio, com a semeadura a lanço de $45 \mathrm{~kg} \mathrm{ha}^{-1}$ de sementes de azevém. A adubação constou de $360 \mathrm{~kg} \mathrm{ha}^{-1}$ de adubo N-P-K (05-20-20) + 140kg/ha de superfosfato triplo. Em cobertura, foram utilizados $67,5 \mathrm{~kg} / \mathrm{ha}$ de nitrogênio na forma de ureia, fracionado em três aplicações iguais.

As avaliações - testes de pastejo - foram realizadas em três datas nos estádios fenológicos do azevém: vegetativo (11/09), pré-florescimento (14/10) e florescimento (11/11), com cinco repetições no estádio vegetativo e seis repetições nos estádios de pré-florescimento e de florescimento. Nas datas de avaliação, as médias de temperatura, insolação, umidade relativa do ar e velocidade do vento foram, respectivamente: $11 / 09-24,6^{\circ} \mathrm{C}, 5,5$ horas/dia, $41 \%$ e $21,9 \mathrm{~km} / \mathrm{h}$; $14 / 10-16,7^{\circ} \mathrm{C}, 6,1$ horas/dia, $71 \%$ e $26,9 \mathrm{kmh}$; $11 / 11-15,9^{\circ} \mathrm{C}, \quad 11,3$ horas/dia, $36,5 \%$ e $36,3 \mathrm{~km} / \mathrm{h}$, dados obtidos na Estação Meteorológica da UFSM, Departamento de Fitotecnia.

Foram utilizadas oito cordeiras por avaliação, sendo que, em três delas, foi medido o processo de ingestão e, em duas, foram mensuradas as perdas de peso insensíveis. As demais foram utilizadas para compor o efeito de grupo durante os testes de pastejo. As cordeiras, cruzas Ile de France $\mathrm{x}$ Texel, com oito meses de idade,

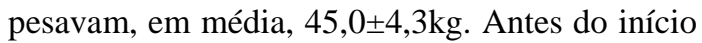
dos testes de pastejo, foram colocadas fraldas geriátricas - coletores de fezes e urina nas cordeiras, e elas não mudaram o seu comportamento ingestivo, sendo, então, consideradas como adaptadas ao experimento.

Foram realizados pastejos com lotação intermitente, e o intervalo entre os pastejos foi determinado pela soma térmica de 313 graus/dia, necessários para o surgimento de 2,5 folhas de azevém (Confortin et al., 2007). Os testes de pastejo foram realizados no resíduo pós-pastejo, com oferta de forragem (kg MS por $100 \mathrm{~kg}$ de PV) média de $13,7 \%$.

O protocolo correspondente a cada teste de pastejo, adaptado de Penning e Hooper (1985), foi: após jejum de oito horas, as cinco cordeirasteste foram vestidas com as fraldas geriátricas com peso conhecido e pesadas em balança digital com precisão de $5 \mathrm{~g}$. Três cordeiras-teste foram encaminhadas à área experimental, em conjunto com os animais de grupo, enquanto as outras duas cordeiras-teste permaneceram em área cercada com piso ripado, próxima à área experimental, sem acesso ao consumo de água e 
alimentos. Nesses animais foram medidas as perdas de peso insensíveis por diferença de massa corporal entre as pesagens.

Cada teste de pastejo teve duração de 45 minutos, e, durante esse tempo, foi efetuada a contagem do número de bocados totais realizados por animal, utilizando-se contadores. Também foi efetuada a marcação do tempo de alimentação, correspondente ao período efetivo de captura de forragem, em que os cronômetros eram desativados nos intervalos intrarrefeição (Gibb, 1998) e ativados novamente quando as cordeiras voltavam a pastar.

Ao final de cada teste de pastejo, os animaisteste e os coletores de excrementos foram pesados novamente. Nos intervalos entre os testes, de aproximadamente uma hora, os animais permaneceram em área cercada com acesso à água. Antes e após cada teste de pastejo, foram realizadas medições da altura média do dossel, sempre pelos mesmos avaliadores, em 300 pontos, distribuídos em trinta transectas localizadas com espaçamento de $1,6 \mathrm{~m}$ entre si. O valor em centímetro, obtido pela diferença entre as alturas final e inicial, foi considerado como a profundidade do bocado.

A partir dos valores obtidos pela diferença de peso das cordeiras e dos coletores de fezes e urina, antes e após o pastejo, calculou-se o consumo de forragem pela equação: $\mathrm{C}=\{\mathrm{P} 2+[(\mathrm{PCf}+\mathrm{F}+\mathrm{U})-\mathrm{PCi}]+\mathrm{PPI}\}-\mathrm{P} 1$, em que C é o consumo de forragem ( $\mathrm{g}$ de matéria verde (MV); P1 é o peso dos animais antes; e P2 é o peso após o pastejo; PCi é o peso inicial do coletor, antes do teste; $(\mathrm{PCf}+\mathrm{F}+\mathrm{U})$ é o peso final do coletor mais fezes e urina após o teste de pastejo; PPI é a perda de peso insensível. O valor do consumo de forragem ( $g$ de $\mathrm{MV}$ ) foi multiplicado pelo teor de MS do pasto e deu origem ao consumo em $\mathrm{g}$ de MS, que foi utilizado para o cálculo da massa do bocado e da taxa de ingestão de MS.

A massa do bocado (mg de MS) foi obtida pelo quociente entre o consumo ( $\mathrm{g}$ de $\mathrm{MS}$ ) e o número de bocados totais; a taxa de ingestão ( $\mathrm{g}$ de $\mathrm{MS} / \mathrm{min}$ ) foi calculada por meio do quociente entre o consumo ( $g$ de MS) e o tempo de alimentação. O valor da taxa de bocados (bocados/min) foi calculado pela relação entre o número de bocados e o tempo de alimentação, e o valor do tempo por bocado (min/bocados) é inversamente proporcional a essa medida.

No dia anterior à realização dos testes de pastejo, foram realizadas as seguintes medidas no pasto: massa foliar (MF), em kg/ha de MS, avaliada por meio do método de estimativa visual com dupla amostragem (T’Mannetje, 2000); altura média do dossel juntamente com a avaliação de MF, com a utilização de uma régua graduada em $\mathrm{cm}$; e estrutura vertical da pastagem, avaliada por meio de cortes de amostras de forragem a cada estrato de $10 \mathrm{~cm}(0-10 ; 10-20 ; 20-30 ; 30-40$ e $+40 \mathrm{~cm})$, em dois pontos na área experimental.

As amostras de cada estrato foram separadas manualmente em colmo (colmo+bainha da folha) e lâmina foliar. O material foi seco em estufa com circulação forçada de ar a $55^{\circ} \mathrm{C}$ por 72 horas e posteriormente pesado, para a estimativa da participação percentual e em $\mathrm{kg} / \mathrm{ha}$ de $\mathrm{MS}$ de cada componente estrutural da pastagem. A razão entre a massa de folhas e colmos resultou nos valores de relação lâmina:colmo, e essa mesma relação foi calculada a partir das massas de lâminas e colmos no estrato superior do dossel $(20-30 \mathrm{~cm})$, resultando na variável relação lâmina:colmo no estrato superior.

A simulação de pastejo foi realizada no dia anterior a cada teste de pastejo por dois avaliadores treinados. Nessa ocasião, uma amostra de forragem semelhante à consumida pelos animais-teste foi coletada manualmente. As amostras foram pesadas, secas em estufa com circulação forçada de ar a $55^{\circ} \mathrm{C}$ por 72 horas, pesadas novamente e moídas em moinho tipo Wiley para análises do teor de proteína bruta pelo método de Kjeldahl (Official..., 1990) e do teor de fibra em detergente neutro (Robertson e Van Soest, 1981).

O delineamento experimental foi o inteiramente casualizado, com medidas repetidas no tempo, com três tratamentos e cinco repetições no tempo (testes de pastejo), no estádio vegetativo e seis nos estádios pré-florescimento e florescimento. Foram realizados análise de variância e teste $\mathrm{F}$ para as variáveis descritoras da pastagem pelo procedimento GLM e quando houve diferença entre as médias, foi aplicado o teste de Tukey a $10 \%$ de significância. Foram realizados análise de variância e teste $F$, utilizando-se o procedimento MIXED, para as variáveis de 
ingestão de MS e de comportamento ingestivo. Foi utilizado o modelo "componente de variância (VC)", selecionado por meio de análise de seleção da estrutura, utilizando-se o critério de informação de Akaike (AIC). Quando houve diferença significativa entre os tratamentos, foi testada análise de regressão polinomial até segunda ordem para os dias de utilização do azevém, e os pontos de máxima e mínima foram calculados por derivação. Para identificar as variáveis independentes com influência sobre as variáveis de comportamento ingestivo, foi utilizado o procedimento STEPWISE. Para medir o nível de associação entre as variáveis de comportamento ingestivo e as variáveis da pastagem, foram realizados testes de correlação linear de Pearson em nível de $10 \%$ de significância. Os dados foram analisados utilizando-se o pacote estatístico SAS (2001), versão 8.2.

\section{RESULTADOS E DISCUSSÃO}

Houve diferença entre estádios fenológicos para a altura do pasto $(\mathrm{P}<0,0001$; Tab. 1). No estádio vegetativo, a altura do dossel foi $81,5 \%$ superior aos $13 \mathrm{~cm}$ recomendados para assegurar o melhor desempenho em cordeiros (Carvalho et al., 2006). A taxa de bocados (TBOC) foi negativamente influenciada (TBOC $=$ 62,1-1,46altura; $\left.\mathrm{R}^{2}=0,99\right)$ pela altura do pasto somente nesse estádio. É possível que esse valor de altura do pasto não tenha restringido a ingestão de MS pelas cordeiras, pois mudanças na taxa de bocados são consideradas um mecanismo acionado pelos animais em pastejo em resposta à variação na estrutura do pasto (Hodgson, 1990). Para uma menor taxa de bocados, a massa de bocados foi, numericamente, $30 \%$ maior que o valor médio dos demais estádios.

Tabela 1. Características estruturais e composição química do pasto aparentemente consumido e valores médios de consumo, taxa de ingestão de matéria seca, massa do bocado e profundidade de bocado de cordeiras em pastagem de azevém em diferentes estádios fenológicos ( $\mathrm{V}=$ vegetativo; $\mathrm{PF}=$ préflorescimento; $\mathrm{F}=$ florescimento)

\begin{tabular}{|c|c|c|c|c|c|}
\hline Variável & $\mathrm{V}$ & $\mathrm{PF}$ & $\mathrm{F}$ & $\mathrm{M}$ & $\mathrm{EP}$ \\
\hline Altura do pasto $(\mathrm{cm})$ & $23,6 a$ & $16,7 \mathrm{~b}$ & $15,7 \mathrm{~b}$ & 18,4 & 1,7 \\
\hline Teor de matéria seca (MS, \%) & $19,5 \mathrm{c}$ & $24,5 \mathrm{~b}$ & $28,8 \mathrm{a}$ & 24,4 & 3,8 \\
\hline Fibra em detergente neutro $(\%)$ & $43,1 b$ & $49,9 a$ & $48,2 \mathrm{a}$ & 47,3 & 3,2 \\
\hline Proteína bruta $(\%)$ & 20,7 & 18,6 & 12,7 & 17,1 & 0,9 \\
\hline Relação lâmina:colmo & 0,43 & 0,21 & 0,33 & 0,32 & 0,1 \\
\hline Relação lâmina:colmo ES* & 0,74 & 0,61 & 0,67 & 0,67 & 0,3 \\
\hline Densidade de lâminas (kg de MS/cm) ES* & 8,8 & 3,2 & 3,2 & 5,1 & 3,4 \\
\hline Densidade de lâminas (kg de MS/cm)EINT* & 28,8 & 4,8 & 6,4 & 14,4 & 5,5 \\
\hline Densidade de lâminas (kg de MS/cm)EINF** & 44,4 & 19,2 & 5,6 & 24,4 & 11,4 \\
\hline Densidade de colmos (kg de MS/cm)ES* & 16,8 & 8,8 & 4,8 & 8,0 & 7,9 \\
\hline Densidade de colmos ( $\mathrm{kg}$ de MS/cm)EINT* & 64,0 & 35,8 & 16,5 & 42,1 & 15,8 \\
\hline Densidade de colmos (kg de MS/cm)EINF* & 136,8 & 117,6 & 19,2 & 91,2 & 19,7 \\
\hline Consumo de forragem (g de MV) & $954,3 \mathrm{a}$ & $610,9 b$ & $697,1 b$ & 742,3 & 252 \\
\hline Consumo de forragem (g de MS) & 187,0 & 149,7 & 198,7 & 177,9 & 62,4 \\
\hline Taxa de ingestão (g de MS/min) & 4,79 & 3,49 & 4,48 & 4,2 & 1,4 \\
\hline Massa do bocado (mg de MS) & 173,5 & 137,1 & 130,6 & 145,5 & 48,0 \\
\hline Profundidade de bocado $(\mathrm{cm})$ & 2,9 & 3,6 & 3,1 & 3,2 & 1,3 \\
\hline
\end{tabular}

Médias seguidas de letras minúsculas distintas, na linha, diferem entre si pelo teste Tukey $(\mathrm{P}<0,05) ; \mathrm{M}-$ média; $\mathrm{EP}=$ erro-padrão; *ES= estrato superior $(20-30 \mathrm{~cm})$; EINT= estrato intermediário $(10-20 \mathrm{~cm})$; EINF= estrato inferior $(0-$ $10 \mathrm{~cm})$.

Nos estádios pré-florescimento e florescimento, a altura do pasto foi $24,7 \%$, em média, maior que a recomendada por Carvalho et al. (2006) e determinou de forma positiva $\left(\mathrm{R}^{2}=0,98 \mathrm{e}\right.$ $\mathrm{R}^{2}=0,99$, respectivamente) $\mathrm{o}$ tempo de alimentação, provavelmente pela estreita relação existente da altura do pasto com as dimensões do bocado (Illius e Gordon, 1999) define a quantidade de alimento a ser ingerido em um bocado e, consequentemente, o tempo que o animal passa se alimentando. 
A composição química do pasto aparentemente consumido pelas cordeiras foi diferente $(\mathrm{P}<0,05)$ entre os estádios fenológicos. $\mathrm{O}$ teor de fibra em detergente neutro (FDN) foi mais baixo no estádio vegetativo e semelhante nos demais estádios $(\mathrm{P}=0,0091)$, e o teor de proteína bruta $(\mathrm{PB})$ diminuiu linearmente $(\mathrm{PB}=38,17-0,14 \mathrm{dia}$; $\left.\mathrm{P}<0,0001 ; \mathrm{R}^{2}=0,86 ; \quad \mathrm{CV}=8,3 \%\right)$ a partir do primeiro dia de utilização da pastagem. Durante toda a utilização da pastagem, as cordeiras colheram o pasto com teor de FDN 21,6\% menor que o valor considerado limitante ao consumo de forragem (Van Soest, 1994) e com teor de PB, mesmo no estádio de florescimento do azevém, $24,5 \%$ maior que as exigências percentuais de ingestão de PB pelas cordeiras (Nutrient..., 2007).

A intensidade de desfolha imposta à pastagem, $30 \%$ de remoção da biomassa existente, provavelmente não estimulou o perfilhamento do azevém no estádio vegetativo, ocorrendo, como consequência, alongamento precoce dos entrenós e menor emissão de folhas, o que ocasionou relação lâmina:colmo (RLC) semelhante aos demais estádios $(\mathrm{P}=0,212)$, com valor médio de 0,32 , a qual pode ser considerada baixa em relação ao valor de 2,3 observado por Roman et al. (2007).

A profundidade de bocado foi semelhante $(\mathrm{P}=0,721)$ nos estádios fenológicos do azevém, com valor médio de $3,2 \mathrm{~cm}$, indicando que, durante todo o ciclo do azevém, as cordeiras pastejaram preferencialmente o estrato superior da pastagem $(20-30 \mathrm{~cm})$.

A RLC no estrato superior (ES) não foi diferente entre os estádios fenológicos $(\mathrm{P}=0,899)$, apresentando valor médio de 0,67 (Tab. 1) e $109,4 \%$ maior que o valor de RLC do dossel. A profundidade de bocado apresentou uma correlação positiva com a massa de lâminas foliares $(\mathrm{r}=0,99 ; \mathrm{P}=0,087)$, e essa associação, juntamente com os dados de qualidade do pasto aparentemente colhido pelas cordeiras e os valores de RLC no ES, pode apontar que a estrutura superior da pastagem permitiu que as cordeiras selecionassem lâminas foliares durante toda a utilização da pastagem.

A profundidade de bocados (PBOC), em todos os estádios fenológicos, foi determinada positivamente pela altura do pasto $\left(\mathrm{R}^{2}\right.$ parcial $=$ $0,32)$ e negativamente pela densidade de colmos no estrato superior $\left(R^{2}\right.$ parcial $\left.=0,35\right)$, com $R^{2}$ total de 0,67 (PBOC= 4,04-0,01alt + 0,06dces). Também Cosgrove (1997) observou, em pastagens de clima temperado, correlação positiva entre altura da pastagem e profundidade de bocado, e o fato de que essa característica parece não ter limitação imposta pelas características anatômicas da boca do animal, apresentando-se mais como uma resposta comportamental às características da pastagem, tal como a participação de colmos no estrato preferencialmente pastejável. Os colmos teriam agido como uma barreira, fazendo com que as cordeiras realizassem bocados rasos, se 0 conceito de proporcionalidade de remoção de forragem de $50 \%$ for considerado (Hodgson et al., 1994).

O teor de MS do pasto diferiu entre estádios fenológicos $(\mathrm{P}=<0,0001)$ e, mesmo no estádio vegetativo, foi superior ao valor de $18 \%$ considerado limitante ao consumo (Alberto, 1997). O teor de MS aumentou $47,7 \%$ entre o estádio vegetativo e o florescimento e pode explicar por que o valor de $\mathrm{MB}$ foi semelhante $(\mathrm{P}=0,27)$ nos estádios fenológicos (Tab. 1). Mesmo que o consumo de forragem verde ( $\mathrm{g} \mathrm{MV}$ ) tenha sido diferente entre os estádios $(\mathrm{P}=0,087)$, com uma redução de aproximadamente $31,5 \%$ do estádio vegetativo para o florescimento, a massa do bocado (MB) foi semelhante, pois esta não resulta apenas da geometria do bocado como descrito na literatura por Ungar (1996), mas também da alteração na concentração de massa por unidade de superfície de folha (Palhano et al., 2007).

Com a pastagem sob oferta de forragem de $14 \%$, em média, a taxa de ingestão foi semelhante $(\mathrm{P}=0,414)$ ao longo do ciclo do azevém, o que pode indicar que não houve limitação ao consumo de pasto mesmo quando o azevém encontrava-se nos estádios pré-florescimento e florescimento. Frente a uma massa de bocados semelhante, no decorrer do ciclo do pasto, as cordeiras passaram mais tempo se alimentando (Fig. 1A), o que resultou em maior número total de bocados (Fig. 1B), mantendo, assim, a taxa de ingestão constante durante toda a utilização do azevém. 

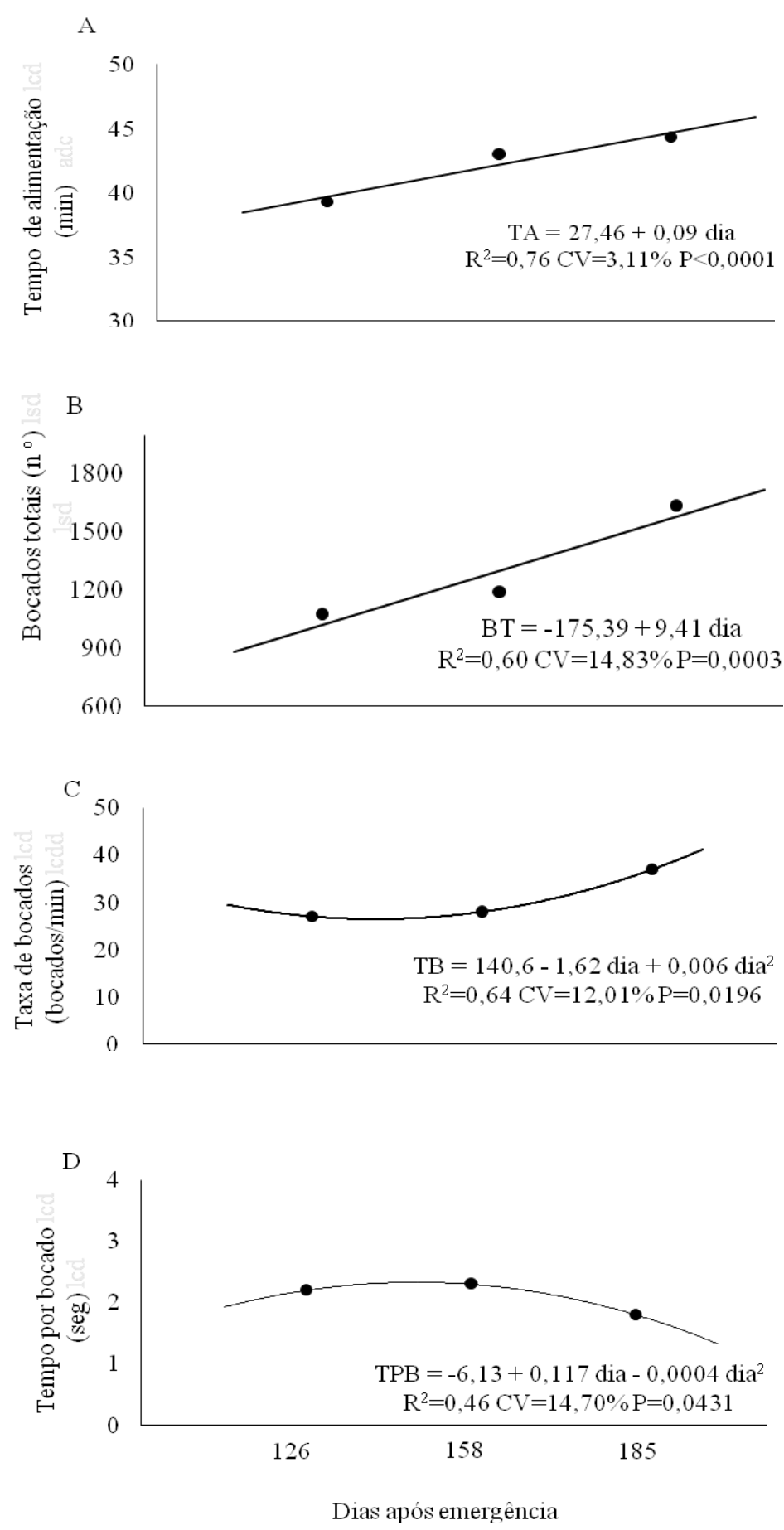

Figura 1. Equações de regressão para as variáveis do comportamento ingestivo de cordeiras em pastagem de azevém, em função dos dias do ciclo (dia 126= vegetativo; dia 158= pré-florescimento; dia 185= florescimento). 
A taxa de bocados e o tempo por bocado apresentaram relação quadrática com os dias de utilização da pastagem (Fig. 1C e 1D). As cordeiras realizaram menor número de bocados por unidade de tempo no $135^{\circ}$ dia após a emergência do azevém, e o maior tempo de formação do bocado foi no $146^{\circ}$ dia do ciclo, com um aumento na frequência dos bocados após essas datas, que corresponderam ao período de transição entre o estádio vegetativo (avaliação no $126^{\circ}$ dia) e o pré-florescimento (avaliação no $158^{\circ}$ dia). A partir desta fase de transição, o aumento no número e na frequência de bocados por minuto realizados pelas cordeiras, para manter a taxa de ingestão constante, pode ter sido ocasionado pela redução numérica da densidade volumétrica de lâminas foliares no estrato superior, que foi de $175 \%$ (Tab. 1).

\section{CONCLUSÕES}

Em azevém, com oferta de forragem de forragem não limitante ao consumo (14\%), a taxa de ingestão de MS por cordeiras é semelhante nos estádios vegetativo, pré-florescimento e florescimento. $\mathrm{O}$ aumento na taxa de bocados é o mecanismo utilizado para manter a taxa de ingestão constante. Os modelos indicam que, dentre os atributos do pasto, sua altura é o de maior importância para determinar mudanças nas variáveis do comportamento ingestivo.

\section{REFERÊNCIAS}

ALBERTO, E. Efectos de la calidad de los forrajes y la suplementación en el desempeño de rumiantes en pastoreo. In: SIMPÓSIO SOBRE AVALIAÇÃO DE PASTAGENS COM ANIMAIS, 1997, Maringá. Anais... Maringá:Universidade Estadual de Maringá, 1997. p.53-73.

ALLDEN, A.W. Rate of herbage intake and grazing time in relation to herbage availability. AUSTRALIAN SOCIETY OF ANIMAL PRODUCTION, 4., 1962. Proceedings... 1962. p.163166.

ALLDEN, W.G.; WHITTAKER, I.A.McD. The determinants of herbage intake by grazing sheep: the interrelationship of factors influencing herbage intake and availability. Aust. J. Agric. Res., v.21, p.755-766, 1970.

CARVALHO, P.C.F.; OLIVEIRA, J.O.R.; PONTES, L.S. et al. Características de carcaça de cordeiros em pastagem de azevém manejada em diferentes alturas. Pesq. Agrop. Bras., v.41, p.193-1198, 2006.
CONFORTIN, A.C.C.; ROCHA, M.G.; QUADROS F.L.F. et al. Características morfogênicas de azevém (Lolium multiflorum Lam.) sob diferentes intensidades de desfolha. In: CONGRESSO BRASILEIRO DE ZOOTECNIA, 17., 2007, Londrina, PR. Anais... Londrina: Sociedade Brasileira de Zootecnia, 2007. CD.

COSGROVE, G.P. Grazing behavior and forage intake. In: SIMPÓSIO INTERNACIONAL SOBRE PRODUÇÃO DE ANIMAIS EM PASTEJO. 1997. Viçosa, 1997. Anais... Viçosa: Universidade Federal de Viçosa, p.59-80.

GIBB, M. Animal grazing/intake terminology and definitions. In: PASTURE ECOLOGY AND ANIMAL INTAKE, 3., 1996, Dublin. Proceedings... Dublin, 1998. p.21-37.

GONÇALVES, E.N. Comportamento ingestivo de bovinos e ovinos em pastagem natural da Depressão Central do Rio Grande do Sul. 2007. 127f. Tese (Doutorado em Zootecnia) - Faculdade de Agronomia, Univeridade Federal do Rio Grande do Sul, Porto Alegre.

HODGSON, J.; CLARK, D.A.; MITCHELL, R.J. Foraging behaviour in grazing animals and its impact on plant communities. In: FAHEY, G.B.C.; COLLINS, M.; MERTENS, D.R. et al. (Eds.). Forage quality, evaluation and utilization. Lincoln: American Society of Agronomy, 1994. Cap. 19. p.796-827.

ILLIUS, A.W.; GORDON, I.J. The physiological ecology of mammalian herbivory. In: INTERNATIONAL SYMPOSIUM ON THE NUTRITION OF HERBIVORES, 6., 1999, Savoy. Proceedings... Savoy, 1999. p.407-423.

LACA, E.A.; DEMMENT, M.W. Modelling intake of a grazing ruminant in a heterogeneous environment. In: INTERNATIONAL SYMPOSIUM ON VEGETATION: HERBIVORE RELATIONSHIPS, 1992, New York. Proceedings... New York, 1992. p.57-76.

NUTRIENT requirements of small ruminants. Washington: National Academy, 2007. 362p.

OFFICIAL methods of analysis. 15.ed. Washington: AOAC, 1990.

PALHANO, A.L.; CARVALHO, P.C.F.; DITTRICH, J.R.D. et al. Características do processo de ingestão de forragem por novilhas holandesas em pastagens de capim-mombaça. Rev. Bras. Zootec., v.36, supl., p.1014-1021, 2007.

PENNING, P.D.; HOOPER, G.E. An evaluation of the use of short-term weight changes in grazing sheep for estimating herbage intake. Grass Forage Sci., v.40, p.79-84, 1985. 
ROBERTSON, J.B.; VAN SOEST, P.J. The detergent system of analysis. In: JAMES, W.P.T.; THEANDER, $\mathrm{O}$. The analysis of dietary fiber in food. New York: Marcel Dekker, 1981. Cap. 9, p.123-158.

ROMAN, J.; ROCHA, M.G.; PIRES, C.C. et al. Comportamento ingestivo e desempenho de ovinos em pastagem de azevém anual (Lolium multiflorum Lam.) com diferentes massas de forragem. Rev. Bras. Zootec., v.36, p.780-788, 2007.

SAS INSTITUTE. Statistical analysis user's guide. Version 8.2. Cary, 2001. 1686p.
T'MANNETJE, L. Measuring biomass of grassland vegetation. In: T'MANNETJE, L.; JONES, R.M. (Eds.). Field and laboratory methods for grassland and animal production research. Cambridge: CABI, 2000. p.151-178.

UNGAR, E.D. Ingestive behavior. In: HODGSON, J.; ILIUS, A.W. The Ecology and Management of Grazing Systems. Oxon: CAB International, 1996. Cap. 7, p.185-218.

VAN SOEST, P.J. Nutritional ecology of the ruminant. 2.ed. Ithaca: Cornell University, 1994. 